\title{
Caught napping in the time of tropical diseases
}

\author{
Niranjan Kissoon, MBBS*; Tim Uyeki, $\mathrm{MD}^{\dagger}$
}

Airline deregulation in 1978 and optimization of routes have been a boon to foreign travel, including to and from Canada, which has one of the fastest growing populations of the G8 countries. ${ }^{1}$ Millions of overseas tourists visit Canada each year. More than $20 \%$ (almost 7 million) of Canada's population is foreign born, with at least $50 \%$ of new immigrants arriving from tropical locales. Recent immigrants may travel to and from their countries of origin. ${ }^{2,3}$

Some travelers may visit tropical and subtropical developing countries and be exposed to infectious diseases that are nonendemic to Canada (e.g., dengue, malaria, chikungunya, typhoid, Japanese encephalitis, cholera, measles) or other uncommon diseases (drug-sensitive, multidrug-resistant, or extensively drug-resistant tuberculosis). Travelers and migrants with some of these diseases pose a transmission risk to close contacts and health care personnel. ${ }^{4}$ Importation of infectious diseases into Canada may occur through air or cruise ship travelers from areas of the world where respiratory viruses may be circulating (e.g., seasonal influenza A and B viruses), and unsuspecting clinicians may not administer appropriate treatment., ${ }^{5,6}$ One can hypothesize that emergency medicine is practiced in Canada in a climate potentially sprinkled with imported tropical diseases.

The report of Meshkat and colleagues in this issue of the journal supports this contention. ${ }^{7}$ They reviewed the literature, conducted an anonymous online survey of emergency physicians, and reviewed major academic emergency medicine conferences and journals to identify gaps in knowledge and ability to treat common tropical diseases. They found few reports, mostly retrospective case reviews, and even fewer with an emergency medicine focus. Overall, $70 \%$ of respondents reported scant exposure during training and lack of comfort with management skills of tropical diseases, and most $(77 \%)$ perceived that they needed further training. There were few continuing medical education (CME) courses $(6$ of 2,038$)$ related to tropical diseases available to Canadian emergency physicians. Although these findings are not surprising, they are troublesome and reflected as incorrect answers to the vignettes provided. Although there are limitations to the study, a more thorough review will not change the present findings that many emergency physicians are unprepared to treat tropical diseases.

When faced with a febrile patient with an unrecognized illness acquired in the tropics, these findings suggest that some emergency physicians might ask the wrong questions, think of the wrong diagnosis, or administer the wrong treatment, with poor outcomes (e.g., untreated malaria complications leading to intensive care unit admission, death). Although such an illness might be common in the tropics and subtropics, Canadian physicians may be unfamiliar with both the disease and the proper management. Misdiagnosis of a disease that has the potential to spread through respiratory transmission (e.g., measles, tuberculosis) may affect other exposed patients and health care personnel who did not use appropriate protective equipment. It may also endanger family members and the community at large.

Recently, two novel respiratory viruses have emerged, which cause human infections resulting in severe and fatal lower respiratory tract disease. The avian influenza A (H7N9) viral infection in humans (case fatality $28 \%$ ) is thought to be primarily zoonotic, following exposure to infected poultry in China. ${ }^{8-10} \mathrm{To}$

From the *Department of Pediatrics and Emergency Medicine, Faculty of Medicine, University of British Columbia, Vancouver, BC, and + National Center for Immunization and Respiratory Diseases, Centers for Disease Control and Prevention - Influenza Division, Atlanta, GA.

Correspondence to: Dr. Niranjan Kissoon, Department of Pediatrics and Emergency Medicine, Faculty of Medicine, University of British Columbia, 4480 Oak Street, Room B 245, Vancouver, BC V6H 3 V4.

This article has been peer reviewed. 
date, one case was exported to Taiwan. ${ }^{11}$ Middle East respiratory syndrome coronavirus (MERS-CoV) infections have occurred in the Middle East (Saudi Arabia, Jordan, Qatar, United Arab Emirates), with exportation to other countries, including the United Kingdom, Germany, France, Italy, and Tunisia. ${ }^{12-14} \mathrm{MERS}-\mathrm{CoV}$ is related genetically to severe acute respiratory syndrome coronavirus (SARS-CoV), raising memories of the Toronto SARS outbreak in 2003, but the case fatality $(46 \%)$ as of August 30, 2013, is far higher than for SARS. ${ }^{15}$ The source of MERS-CoV is currently unknown. Limited nonsustained human-to-human transmission of $\mathrm{H} 7 \mathrm{~N} 9$ virus, as well as MERS-CoV, has occurred (including nosocomial transmission), raising global public health concerns. ${ }^{9,13,14}$ For both viral infections, a history that elicits recent travel (to China for H7N9 virus and the Middle East for MERS-CoV), contact with animals (including poultry), or exposure to an ill close contact is essential to raise clinical suspicion. Many Canadians will travel to and from Saudi Arabia from September to November 2013 for the October Hajj, prompting MERS-CoV transmission, amplification, and exportation concerns. To date, such exported cases are very rare worldwide, and emergency physicians should be aware of the potential for patients arriving from other countries and presenting with febrile acute respiratory illnesses potentially caused by novel respiratory viruses.

Adherence to recommended infection control measures is critical to preventing nosocomial transmission of both common and novel respiratory pathogens of public health concern in the emergency department. ${ }^{16}$ Maintaining standard precautions at all times, implementing isolation or cohorting, and employing contact and droplet precautions for patients with respiratory symptoms will help reduce transmission of known and novel respiratory diseases. Improved disease monitoring, laboratory-based surveillance, and closer ties between the public health community and emergency clinicians are needed to facilitate appropriate clinical management (including infection control) and to respond promptly to such emerging global threats.

To address knowledge gaps in the management of tropical infectious diseases, a multifaceted approach should be considered. These include promulgating policies requiring global health awareness, tropical and emerging infectious disease education, and management proficiency in medical school curricula; residency training programs; and board certification and recertification in emergency medicine. Based on the findings reported by Meshkat and colleagues, ${ }^{7} \mathrm{CME}$ for practicing clinicians should include case reports, didactic sessions on specific tropical diseases, and approaches to the management of broader clinical syndromes. Such CME should not rely on one particular modality but include online travel medicine webinars, podcasts, and conference workshops in collaboration with professional medical societies in Canada and worldwide. Emergency medicine journals could implement a regular section accessible online focused on the diagnosis and management of tropical infectious diseases and include regular updates on emerging and re-emerging infectious diseases worldwide. This can be done in coordination with infectious disease experts specializing in travel medicine, professional medical societies, local and provincial public health departments, and the Public Health Agency of Canada.

Training must cover how to take a thorough travel history. Based on a history of recent travel and clinical findings, especially with febrile illness, emergency physicians should be encouraged to consult travel medicine and infectious diseases specialists on the clinical management of patients with suspected travelrelated diseases. One way to increase the frequency of asking about a recent travel history is to make it a requirement for hospital accreditation purposes, for all febrile, non-trauma-related emergency medicine patients at triage.

No one approach will make us experts in tropical diseases, but a concerted effort using multiple modalities offers the best chance to close the knowledge gap. This report is a wakeup call, and we need to improve education promptly to recognize, treat, and correctly manage imported diseases, however rare they may be for most Canadian physicians. We should not be caught napping when a tropical disease or novel virus pays an unheralded visit to our emergency department.

Keywords: education, emergency medicine, imported diseases, tropical diseases

Competing interests: None declared.

\section{REFERENCES}

1. Smith FL Jr, Cox B. Airline deregulation. Available at: http:// www.econlib.org/library/Enc/AirlineDeregulation.html (accessed June 18, 2013).

2. Radia A. Canada's population reaches 35 million, fastest growing in the G8. Canada Politics. December 7, 2012. 
Available at: http://ca.news.yahoo.com/blogs/canada-politics/ canada-population-reaches-35-million-fastest-growing-g8174256519.html) (accessed June 18, 2013).

3. The Canadian Press. Canada's foreign-born population soars to 6.8 million. Available at: http://www.cbc.ca/news/canada/ story/2013/05/08/census-statistics-canada-household-survey. html (accessed June 18, 2013).

4. McCarthy AE, Weld LH, Barnett ED, et al. Spectrum of illness in international migrants seen at GeoSentinel clinics in 1997-2009, part 2: migrants resettled internationally and evaluated for specific health concerns. Clin Infect Dis 2013; 56:925-33, doi:10.1093/cid/cis1016.

5. Uyeki TM, Zane SB, Bodnar UR, et al. Alaska/Yukon Territory Respiratory Outbreak Investigation Team. Large summertime influenza A outbreak among tourists in Alaska and the Yukon Territory. Clin Infect Dis 2003;36:1095-102, doi:10.1086/374053.

6. Belderok SM, Rimmelzwaan GF, van den Hoek A, Sonder GJ. Effect of travel on influenza epidemiology. Emerg Infect Dis 2013;19:925-31, doi:10.3201/eid1906.111864.

7. Meshkat N, Misra S, Hunchak C, et al. Knowledge gaps in the diagnosis and management of patients with tropical diseases presenting to Canadian emergency departments: are the gaps being met? Can 7 Emer Med 2014;16:458-66, doi: 10.2310/8000.2013.131265.

8. Gao HN, Lu HZ, Cao B, et al. Clinical findings in 111 cases of influenza A (H7N9) virus infection. N Engl 7 Med 2013 May 22. [Epub ahead of print]

9. Li Q, Zhou L, Zhou M, et al. Preliminary report: epidemiology of the avian influenza A (H7N9) outbreak in China. N Engl 7 Med 2013 Apr 24. [Epub ahead of print]
10. World Health Organization. WHO risk assessment. Human infections with avian influenza A (H7N9) virus 7 June 2013. Available at: http://www.who.int/influenza/human_animal_ interface/influenza_h7n9/RiskAssessment_H7N9_07Jun13. pdf (accessed June 18, 2013).

11. Chang SY, Lin PH, Tsai JC, et al. The first case of H7N9 influenza in Taiwan. Lancet 2013;381:1621, doi:10.1016/ S0140-6736(13)60943-5.

12. Memish ZA, Zumla AI, Al-Hakeem RF, et al. Family cluster of Middle East respiratory syndrome coronavirus infections. N Engl 7 Med 2013 May 29. [Epub ahead of print]

13. Assiri A, Al-TawfiqJA, Al-Rabeeah AA, et al. Epidemiological, demographic, and clinical characteristics of 47 cases of Middle East respiratory syndrome coronavirus disease from Saudi Arabia: a descriptive study Lancet Infect Dis 2013;13: 752-61, doi:10.1016/S1473-3099(13)70204-4.

14. World Health Organization. Middle East respiratory syndrome coronavirus (MERS-CoV) summary and literature update - as of 13 August 2013. Available at: http://www.who.int/csr/ disease/coronavirus_infections/update_20130813/en/index. html (accessed August 30, 2013).

15. World Health Organization. Middle East respiratory syndrome coronavirus (MERS-CoV) - update. Available at: http://www. who.int/csr/don/2013_08_30/en/index.html (accessed August 30, 2013).

16. World Health Organization. Interim Guidance Document. Clinical management of severe acute respiratory infections when novel coronavirus is suspected: what to do and what not to do. Available at: http://www.who.int/csr/disease/coronavirus_ infections/InterimGuidance_ClinicalManagement_Novel Coronavirus_11Feb13u.pdf (accessed June 18, 2013). 